\title{
Analysis of elastic viscoplastic consolidation of sand drain foundations with exponential seepages
}

\author{
Duanyang Yang ${ }^{1}$, Fengyuan $\mathrm{Li}^{1}{ }^{1}$, , Yangyang Xia ${ }^{1}$, Mingsheng Shi ${ }^{1}$, Yanjie Hao ${ }^{1}$, Qi Liu ${ }^{1}$ \\ ${ }^{1}$ School of Water Science and Engineering, Zhengzhou University, Zhengzhou 450000, China
}

\begin{abstract}
Studies have shown that the pore seepage in soft clay deviates from Darcy's law, with the compressibility and permeability of the soil demonstrating obvious nonlinear characteristics during the consolidation process. These factors will affect the sand drain foundation consolidation process. In order to explore the consolidation mechanism of sand drain foundation in saturated clay, this paper introduces the UH model considering the time effect to describe the nonlinear deformation relation of the soil skeleton under the Barron free strain assumption and introduces the exponential seepage equation as an alternative to Darcy's law. Additionally, the impact of the permeability coefficient and the smearing effect is considered which is used to re-derive the conventional sand drain consolidation equation, and then the finite difference method is adopted to give the implicit numerical solutions of the equation. By comparing with literature results, the validity of the method developed in this paper is verified. Then, the effects of the soil nonlinearity, construction disturbance, and external load on the sand drain foundation nonlinear consolidation process are studied as a function of time. The current results reveal that due to the viscous effect of soil, the pore pressure near the undrained boundary of the sand drain foundation during the pre-loading period increases. The above phenomenon is more evident when considering the non-Darcy seepage; meanwhile, the consolidation rate of the sand drain foundation also becomes increasingly slow. Moreover, the decrease of the permeability coefficient in the smear zone can significantly reduce the dissipation rate of the overall pore pressure of the sand drain foundation, while the increase of the external load accelerates foundation consolidation.
\end{abstract}

\section{Introduction}

Currently, the drainage consolidation method, which is based on the sand drain consolidation theory, is the most common method for the design and evaluation of the soft soil foundation [1]. Barron et al. [2] first conducted a systematic study on the problem of sand drain foundation consolidation. Later, a solution to sand drain consolidation that considered both well resistance and the smearing effect under the assumption of equal strain was provided in $[3,4]$. Based on this solution, the influence of factors such as the non-uniform distribution of initial pore pressure, boundary water permeability, variable well resistance effect, smear zone permeability coefficient and applied load changes were further explored, making the classic sand drain consolidation theory more adequate [59]. However, the applicability of this theory in the soft clay area has always been questionable. This is mainly because numerous engineering data shows that there are often large differences between theoretical and actual values, which are mainly due to the assumption that both soft clay deformation and pore seepage are in a linear relation, and the influence of rheological properties is ignored.

The problem of soil deformation nonlinearity is longstanding. It was confirmed through laboratory compression tests that soft clay deformation had obvious nonlinear characteristics, and that it was generally described by the compression or consolidation coefficient [10-11]. The idealized compression nonlinear relationship was first introduced to analyze the radial consolidation of sand drains $[12,13]$. The results demonstrated that the consolidation rate of foundations is indeed significantly lower. Since then, many researchers have conducted indepth studies. For instance, Zhou et al. [14] discussed the impact of loading ratio on the consolidation rate of sand drains; the sand drain foundation consolidation characteristics under the smear zone permeability coefficient were analyzed $[15,16]$; the solution of nonlinear consolidation of sand drains considering the effect of well resistance was given [17, 18]; Guo et al. [19] discussed the vacuum attenuation, variable load and other factors for the vacuum preload foundation. However, all these previous studies did not consider the rheological properties of soil [20-22], which is one of the reasons for the large deviation of the current analysis of consolidation for soft clay foundation. Finally, an attempt was made to introduce a component model to describe the rheological properties of soil. For instance, based on the Merchant model or fractional Merchant model, the sand drain foundation was analyzed by viscoelastic consolidation [23-25]. This component model has numerous parameters and is quite complicated [26], however, the plastic deformation of soil is ignored. Recently, Yao et al. [27-28]

\footnotetext{
*Corresponding author: liyangwy163yx@163.com
} 
proposed a novel unified hardening constitutive model (UH model) based on the corrected Cambridge model by introducing unified hardening parameters and Hvorslev strength envelope and then extended it to an elastic-viscoplastic model which considered the effect of time. The model has fewer parameters, which can be determined in common laboratory experiments. Under Darcy's seepage conditions, the UH model considering the effect of time was introduced into the consolidation analysis, and the effects of elastic-visco-plastic parameters on the consolidation process were primarily revealed [29-30].

Some seepage tests revealed that seepages in soft clay do not follow Darcy's law; and these seepages are called non-Darcy seepages [31-33]. Qi et al. [33] tested seepage in the Xiaoshan clay using the GDS consolidation tester and found that the exponential seepage model exhibited optimized fitting performance. Walker et al. [34] introduced the exponential seepage model and studied the sand drain foundation consolidation characteristics regardless of the well resistance effect. Combined with the loading conditions of vacuum preloading, the analytical solutions of sand drain foundation consolidation under the exponential seepage mode were derived [35, 36]. Additionally, piecewise linear seepage and initial hydraulic gradient seepage could also be used to describe the non-linear relation of pore seepage. For instance, the seepage model considering the initial hydraulic gradient and the consolidation characteristics of the non-ideal sand drain foundation were discussed in [37-39]. Based on the Biot consolidation theory [40] and the Terzaghi consolidation theory [41], the degree of change mechanism of sand drain foundation consolidation under Hansbo seepage was analyzed. However, these studies were still based on elastoplastic deformation theory as they did not consider the time effect on soil deformation. As a result, these studies were not able to adequately describe the consolidation characteristics of soft clay foundation.

Despite great advances in the application and development of the sand drain drainage consolidation method, a comprehensive analysis of the effects of nonlinear deformation of a soil skeleton, nonlinear pore seepage, and other factors have been rarely reported. In order to further explore the complex consolidation characteristics of soft soil foundation, this article intends to introduce an exponential seepage model for describing non-Darcy seepage based on previous studies [30], with the influence of disturbance factors in sand drain construction, which are also being considered. The existing nonlinear sand drain consolidation theory is revised, and the effects of relevant parameters on the consolidation process of soft clay foundation are revisited and discussed.

\section{Establishment and solution of calculation models}

\subsection{Introduction of exponential seepage model}

The Slepicka exponential seepage model [32] is introduced to describe the non-Darcy characteristics of soft clay, which can be expressed as

$$
v=k i^{m}
$$

where $\mathrm{v}$ refers to the seepage velocity, $\mathrm{k}$ refers to the seepage coefficient, i refers to the hydraulic gradient and $\mathrm{m}$ refers to the experimental constant. When $\mathrm{m}=1$, it degrades the equation to the conventional Darcy seepage form.

\subsection{Derivation of the governing equation}

The model is schematically shown in Figure 1. This article analyzes the radial consolidation of single well foundations. Suppose a sand drain is located on a saturated homogeneous soft clay foundation in a coastal area along a river. Based on the radial symmetry assumption, the radiuses of the sand drain and the affected area are rw and re respectively, and the well diameter ratio is $n=$ re $/ r w$. Considering the inevitable smearing effect in the actual sand drain construction and if its influence radius is assumed to be rs, there is no excess pore pressure in the foundation, and under the load of its weight it has been completely consolidated. A uniform load p0 is applied instantaneously over a large area of its top surface. Ignoring the effect of well resistance, the other assumptions are the same as in the Barron sand drain consolidation theory. In this manner, a polar coordinate system is set up in which the origin is located in the center of the area. Suppose the effective stress at a distance $r$ from the center of the sand drain at time $t$ is $\sigma^{\prime}$. Based on the previous method [30], the nonlinear sand drain consolidation equation can be derived as follows.

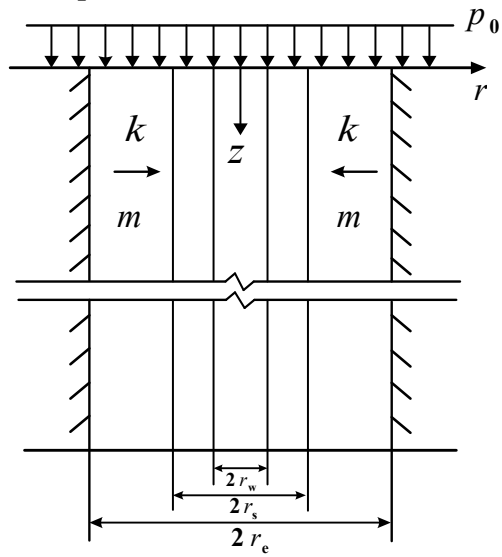

Fig. 1 Analysis model

We first define the permeability coefficient in the foundation consolidation process and consider the influence of the smearing effect:

$$
k=k(r) \exp \left[-\ln 10 \varepsilon_{\mathrm{v}}\left(1+e_{0}\right) / C_{\mathrm{k}}\right]
$$

where $\varepsilon_{\mathrm{v}}$ is the vertical volumetric strain of the foundation; $\mathrm{Ck}$ is the permeability index; $\mathrm{e} 0$ is the initial porosity and $k(r)=k_{\mathrm{h}} f(r)$ is the permeability coefficient that changes continuously along the radial direction, where $\mathrm{f}(\mathrm{r})$ can be calculated by:

$$
f(r)=\left\{\begin{array}{l}
k_{\mathrm{s}} / k_{\mathrm{h}}=\delta \quad r_{\mathrm{w}}<r<r_{\mathrm{s}} \\
1 \quad r_{\mathrm{s}}<r<r_{\mathrm{e}}
\end{array}\right.
$$


Here, $\delta$ is a constant reflecting soil disturbance, $\mathrm{kh}$ is the permeability coefficient in the undisturbed zone and ks is the permeability coefficient in the smear zone.

To facilitate application analysis, Eq (1) is changed to a form similar to Darcy's law:

$$
v=K^{\prime} i
$$

where the permeability coefficient is $K^{\prime}=k i^{m-1}$.

According to the soil seepage continuity condition, the following can be obtained:

$$
\frac{\partial \varepsilon_{\mathrm{v}}}{\partial t}=\frac{\partial v_{\mathrm{r}}}{\partial r}+\frac{v_{\mathrm{r}}}{r}
$$

where vr is the radial seepage velocity, which can be calculated by Eq (4).

Rearranging Eq (5), the consolidation equation [30] can be obtained:

$$
\frac{1}{r} \frac{\partial}{\partial r}\left(\psi r \frac{\partial \sigma^{\prime}}{\partial r}\right)=\phi \frac{\partial \sigma^{\prime}}{\partial t}+\eta
$$

where $\boldsymbol{\sigma}^{\prime}$ is the soil effective stress; coefficient $\psi=K^{\prime} / \gamma_{\mathrm{w}}$

$$
\begin{aligned}
& \eta=C_{\alpha} / {\left[\ln 10\left(1+e_{0}\right)\left(t_{\mathrm{a}}+t_{0}\right)\right], } \\
& \phi=\left\{\begin{array}{l}
\frac{C_{\mathrm{s}}+\left(C_{\mathrm{c}}-C_{\mathrm{s}}\right) M^{4} / M_{\mathrm{f}}^{4}}{\left(1+e_{0}\right) \sigma^{\prime} \ln 10}, \mathrm{~d} \sigma^{\prime} \geq 0 \\
\frac{C_{\mathrm{s}}}{\left(1+e_{0}\right) \sigma^{\prime} \ln 10}, \mathrm{~d} \sigma^{\prime}<0
\end{array}\right.
\end{aligned}
$$

coefficient

The initial and boundary conditions to supplement Eq (6) are:

$$
\begin{gathered}
\sigma^{\prime}(r, 0)=\sigma_{0}^{\prime} \quad r_{\mathrm{w}} \leq r \leq r_{\mathrm{e}} \\
\sigma^{\prime}\left(r_{\mathrm{w}}, t\right)=\sigma_{0}^{\prime}+p_{0} \quad t>0 \\
\frac{\partial \sigma^{\prime}\left(r_{\mathrm{e}}, t\right)}{\partial r}=0 \quad t>0
\end{gathered}
$$

\subsection{Finite difference method}

The above consolidation equation is a second-order parabolic partial differential equation, however, the process of getting its analytical solutions is tedious and difficult. Therefore, this article adopts the implicit finite difference method to find its numerical solutions. In meshing, $\Delta \mathrm{r}$ is used as the step size, the sand drain affected area $r_{\mathrm{w}} \leq r \leq r_{\mathrm{e}}$ is uniformly distributed into $\mathrm{N}$ layers from inside out, and $\Delta \mathrm{t}$ is taken as the time step to uniformly distribute T. Then Eq (6) can be discretized as:

$$
\begin{aligned}
\sigma_{i^{\prime}}^{\prime j+1}= & \sigma_{i^{\prime}}^{\prime j}+\varpi_{i^{\prime}}^{j+1}\left(\psi_{i^{\prime}+1 / 2}^{j+1} r_{i^{\prime}+1 / 2} A_{i^{\prime}}^{j+1}-\psi_{i^{\prime}-1 / 2}^{j+1} .\right. \\
& \left.r_{i^{\prime}-1 / 2} B_{i^{\prime}}^{j+1}\right)+\beta_{i^{\prime}}^{j+1}
\end{aligned}
$$

$$
\begin{aligned}
& \text { where } \quad a_{1}=\Delta t /(\Delta r)^{2} \quad ; \quad \varpi_{i^{\prime}}^{j+1}=a_{1} /\left(\phi_{i^{\prime}}^{j+1} r_{i^{\prime}}\right) \text {; } \\
& \psi_{i^{\prime} \pm 1 / 2}^{j+1}=K_{i \pm 1 / 2}^{\prime j+1} / \gamma_{\mathrm{w}} \quad ; \quad A_{i^{\prime}}^{j+1}=\sigma_{i^{\prime}+1}^{j+1}-\sigma_{i^{\prime}}^{j+1} \text {; } \\
& B_{i^{\prime}}^{j+1}=\sigma_{i^{\prime}}^{j+1}-\sigma_{i^{\prime}-1}^{j+1} \quad ; \quad \beta_{i^{\prime}}^{j+1}=-\eta_{i^{\prime}}^{j+1} \Delta t / \phi_{i^{\prime}}^{j+1}
\end{aligned}
$$

$$
\begin{aligned}
& r_{i^{\prime}}=r_{\mathrm{w}}+i^{\prime} \Delta r \quad ; \quad r_{i^{\prime}+1 / 2}=r_{\mathrm{w}}+\left(i^{\prime}+1 / 2\right) \Delta r \\
& r_{i^{\prime}-1 / 2}=r_{\mathrm{w}}+\left(i^{\prime}-1 / 2\right) \Delta r
\end{aligned} ;
$$

The subscript $i^{\prime}$ takes the values of $1,2,3 \cdots, N-1$; the superscript $\mathrm{j}$ takes the values of 1,2 , $3, \ldots$

The conditions of the equation solutions: that is, Eq (7)-(9) can be discretized as

$$
\begin{gathered}
\sigma_{i^{\prime}}^{\prime 0}=\sigma_{0}^{\prime} \quad i^{\prime}=0,1,2 \cdots, N \\
\sigma_{0}^{\prime j}=\sigma_{0}^{\prime}+p_{0} \quad j=1,2,3 \cdots \\
\sigma_{N}^{\prime j+1}=\sigma_{N}^{\prime j}-\varpi_{N}^{j+1}\left(\psi_{N+1 / 2}^{j+1} r_{N+1 / 2}+\psi_{N-1 / 2}^{j+1} r_{N-1 / 2}\right) . \\
B_{N}^{j+1}+\beta_{N}^{j+1}
\end{gathered}
$$

$\mathrm{Eq}$ (10)-(13) are combined to form a closed system of non-linear equations, which can be solved by an iterative method. Fortran language was used to develop a computer program to solve the effective stress in each node; and then the corresponding pore pressure based on the effective stress principle was calculated. Finally, the average consolidation degree, defined by pore pressure, was introduced to describe the overall consolidation degree of sand drain foundation:

$$
\begin{gathered}
U_{\mathrm{P}}=1-\frac{\int_{r_{\mathrm{w}}}^{r} \mathrm{e} 2 \pi r u d r}{\int_{r_{\mathrm{w}}}^{r} 2 \pi r p_{0} d r}=1-\frac{2 \sum_{j=0}^{N-1} S_{i^{\prime}}^{j}}{p_{0}\left(r_{\mathrm{e}}^{2}-r_{\mathrm{w}}^{2}\right)} \\
S_{i^{\prime}}^{j}=\left[\left(u_{i^{\prime}}^{j} r_{i^{\prime}+\mathbf{1}}-u_{i^{\prime}+\mathbf{1}}^{j} r_{i^{\prime}}\right)\left(r_{i^{\prime}+\mathbf{1}}^{2}-r_{i^{\prime}}^{2}\right) /(\mathbf{2} \Delta r)\right]+ \\
\text { where }\left(u_{i^{\prime}+\mathbf{1}}^{j}-u_{i^{\prime}}^{j}\right)\left(r_{i^{\prime}+\mathbf{1}}^{3}-r_{i^{\prime}}^{3}\right) /(\mathbf{3} \Delta r)
\end{gathered}
$$

\section{Verification}

The results obtained in this study are compared with numerical solutions reported in previous studies [30]. To achieve that, the smearing effect is ignored in calculations. Let $\mathrm{m}=1$, and the other parameters are the same as previous studies [30], that is, $k_{0}=6.0 \times 10^{-7} \mathrm{~m} / \mathrm{min}$, $p_{0}=90 \mathrm{kPa} \quad e_{0}=1.57, \sigma_{0}^{\prime}=10 \mathrm{kPa} \quad C_{\mathrm{c}}=0.6$, $C_{\mathrm{k}}=0.8, C_{\mathrm{s}}=0.12, R_{0}=0.75, M=0.772$, $r_{\mathrm{w}}=0.05 \mathrm{~m}, r_{\mathrm{e}}=1.0 \mathrm{~m}$. As shown in Fig. 2, the results of the two are consistent, indicating that the solving method in this paper is effective. 


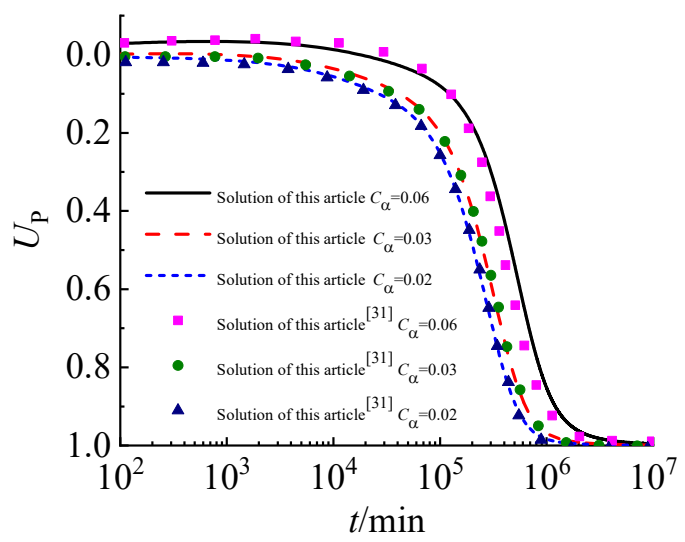

Fig. 2 Average consolidation degree vs. time

\section{Parametric analysis}

The calculation parameters of non-ideal sand drains were selected for the parametric analysis. Bergado et al. [42] suggested that the level of soil permeability coefficient in the non-disturbed zone is 1.5 to 2 times that of the smear zone of laboratory experiments; Madhav et al. [43] considered the smear ratios to be ranging from 1.5 to 4.0 . In this work the calculation parameters were set according to previous studies $[30,35]: k_{\mathrm{h}}=6.0 \times 10^{-7} \mathrm{~m} / \mathrm{min}$, $p_{0}=150 \mathrm{kPa}, \delta=0.75, \sigma_{0}^{\prime}=50 \mathrm{kPa}, C_{\mathrm{c}}=0.6$, $C_{\mathrm{k}}=0.8, \quad C_{\alpha}=0.04, R_{0}=0.75, \quad C_{\mathrm{s}}=0.12$, $M=0.772 \quad, \quad \gamma_{\mathrm{w}}=10 \mathrm{kN} / \mathrm{m}^{3} \quad, \quad r_{\mathrm{w}}=0.1 \mathrm{~m}$ ， $r_{\mathrm{s}}=0.2 \mathrm{~m}, \quad r_{\mathrm{e}}=1.0 \mathrm{~m}, \quad m=1.5, \quad N=45, e_{0}=1.5$, $\Delta t=0.1 \mathrm{~min}$, with the iteration error being $10^{-7}$.

As the elastic viscoplastic consolidation characteristics of ideal sand drain foundations have been already investigated [30], this article only focuses on the analysis of seepages of non-Darcy characteristics, the smearing effect, and other factors on the sand drain foundation consolidation process. In order to facilitate the analysis, the following single factor method is used for analysis. Also, time and pore pressure is normalized by introducing dimensionless parameters:

$$
T=\frac{\ln 10 k_{\mathrm{h}}\left(1+e_{0}\right) \sigma_{0}^{\prime}}{\gamma_{\mathrm{w}} C_{\mathrm{c}} r_{\mathrm{e}}^{2}} t, U=\frac{u}{p_{0}}
$$

where $U$ is the dimensionless pore pressure and $T$ is the dimensionless time.

\subsection{Effects of secondary consolidation coefficient on rheological consolidation}

Under the non-Darcy seepage premise, this article investigates the influence of the soil viscosity on the rheological consolidation of a sand drain foundation. Figure 3 shows the variation curves of pore pressure at the impervious boundary under different secondary consolidation coefficients. As observed, the soil viscosity causes the pore pressure at the impervious boundary to rise rather than dissipate during the beginning of consolidation.
When the viscosity is stronger, the cumulative effect of this pore pressure is more significant, that is, the peak pore pressure is greater. Meanwhile, the time to reach the peak pore pressure is delayed. For instance, secondary consolidation coefficients $\left(\mathrm{C}_{\alpha}\right)$ are set to $0.02,0.04,0.06$, the corresponding peak pore pressures are 1.03, 1.12, 1.18, and the corresponding $\mathrm{T}$ are $0.12,0.15$ and 0.21 .

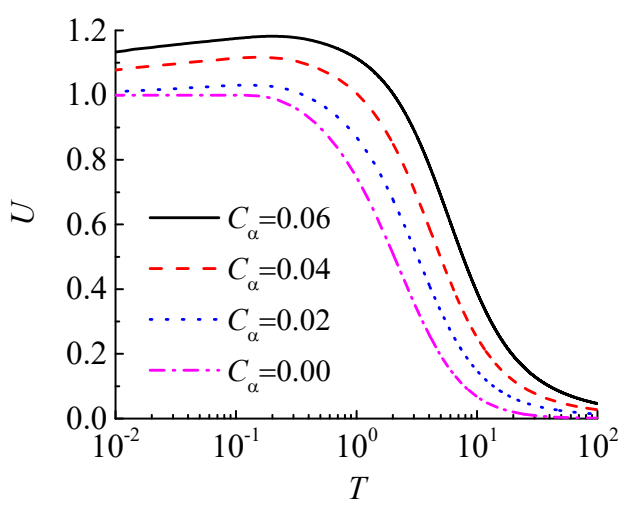

Fig. 3 The effect of secondary consolidation coefficient on pore pressure $(r=1.0 \mathrm{~m})$.

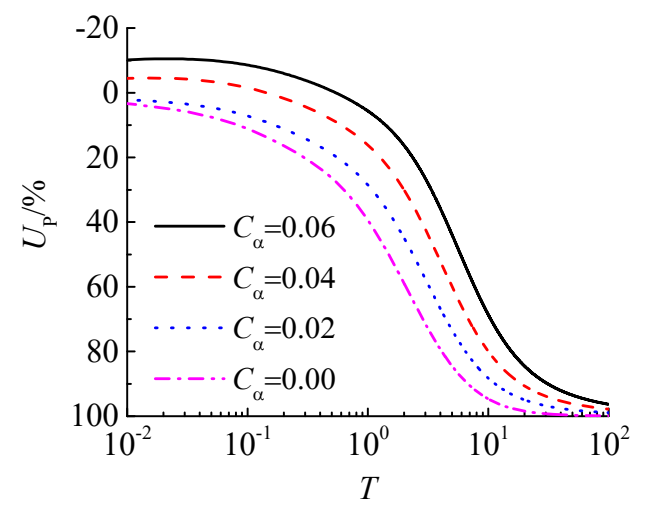

Fig. 4 The effect of the secondary consolidation coefficient on the degree of consolidation

$\mathrm{Hu}$ et al. [29] stated that the increase in pore pressure is due to the poor drainage conditions of the soil and the decrease in effective stress. Liu et al. [30] also agreed with this opinion and showed that this phenomenon was different from the Mandel effect mechanism described by the conventional Biot theory. Clearly, the present analysis also supports the outcomes of these previous studies [2930]. Additionally, if the rheological effect of the soil is not considered, the pore pressure will not increase, but it will dissipate with time. However, it will dissipate quite slowly at the beginning of the consolidation, so the initial value remains unchanged for some time, but then the dissipation process speeds up.

The time dependences of the degree of consolidation $U_{P}$ in Figure 4 reflect that soil viscosity has an impact on the early, middle and late stages of sand drain foundation consolidation, which confirms the primary and secondary consolidation coupling mechanism of soft clay. Additionally, the degree of consolidation, considering the effect of time, shows a negative value in the early stage of consolidation, which is caused by the Mandel-like effect in the larger range of the foundation [30]. Hence, in the consolidation analysis of soft clay foundation, particular 
attention should be paid to the impact of soil rheological effect.

\subsection{Effects of non-Darcy seepage on rheological consolidation}

Figure 5 shows the effect of the exponent seepage parameter $m$ on the pore pressure at the undrained boundary. In the early stage of loading, regardless of the impact of non-Darcy seepage, each pore pressure curve increases. However, with the gradual increase of the parameter $m$, the peak pore pressure rises slightly. This also shows that the non-Darcy characteristics of seepage enhance the "Mandell-like effect". For instance, the peak pore pressures at $\mathrm{m}=1.2,1.5$ and 1.8 are $1.11,1.12$ and 1.13 , respectively, while that at the Darcy seepage is only 1.09. At the same time, it can be seen from Figure 5 that in the middle and at the late stages of consolidation, the pore pressure curve, considering non-Darcy seepage, will deviate significantly from the Darcy seepage curve, and when the value of the seepage parameter $m$ is greater, the degree of deviation is higher. This is similar to the results based on the elastic consolidation analysis [41]. Meanwhile, the difference is that no increase in pore pressure at the beginning of consolidation was identified. This indicates that although the non-Darcy characteristics of soil enhance the "Mandell-like effect" in the early stage of consolidation, they are not the reason behind this phenomenon.

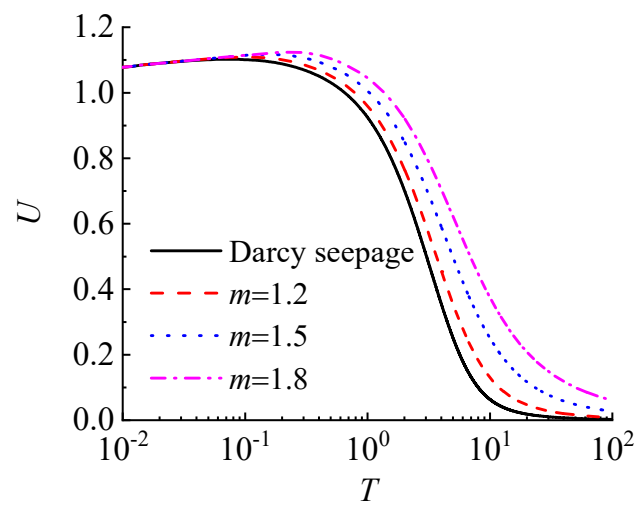

Fig. 5 The effect of the parameter $m$ on the pore pressure.

Figure 6 demonstrates that in the early stage of consolidation, the difference in the consolidation degree curves is very small, which can be explained from Eq (4): the hydraulic gradient of seepage in soft clay in the early stage of consolidation is relatively large, and the effect of seepage parameter $\mathrm{m}$ is small. However, with time, the foundation soil becomes denser, the hydraulic gradient gradually decreases, and the difference of the consolidation degree curves in the middle and late stages of consolidation is exhibited. For instance, when the consolidation degree reaches $90 \%$ of the general requirement, only $\mathrm{t}=7.38$ is required under the Darcy seepage conditions, and the time corresponding to is $\mathrm{m}=1.2,1.5$ and 1.8 is $10.44,18.76$ and 36.14 , respectively. This is similar to the conclusion of previous studies [35], who studied the effect of exponential seepage on the consolidation of vacuum preloading sand drain foundation, that is, non-Darcy seepage hinders the consolidation process of sand drain foundation.

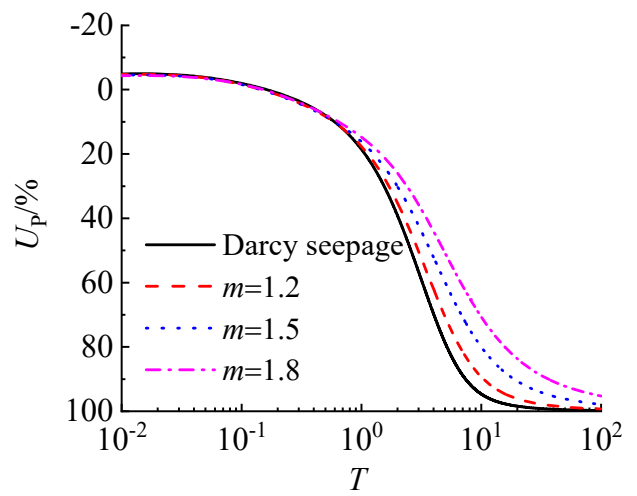

Fig. 6 The effect of the parameter $m$ on the consolidation degree.

\subsection{Effects of smear zone permeability coefficient on rheological consolidation}

Figs. 7 and 8 demonstrate the consolidation characteristics of the sand drain foundation as a function of the smear zone permeability coefficient. In particular, Fig. 7 shows that the disturbance degree of the smear zone soil increases pore pressure at the beginning of consolidation, and as the disturbance degree becomes greater, that is, $\delta$ is smaller, this phenomenon is more evident. Meanwhile, in the middle and late stages of consolidation, the reduction of smear zone seepage coefficient is also not conducive to the dissipation of pore pressure.

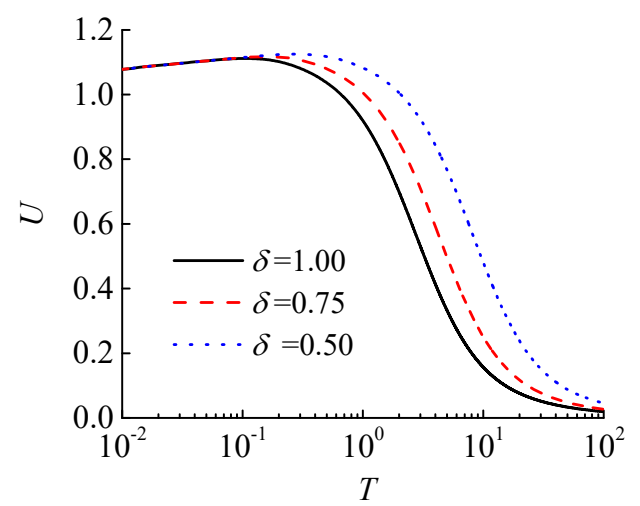

Fig.7 The effect of the parameter $\delta$ on the pore pressure.

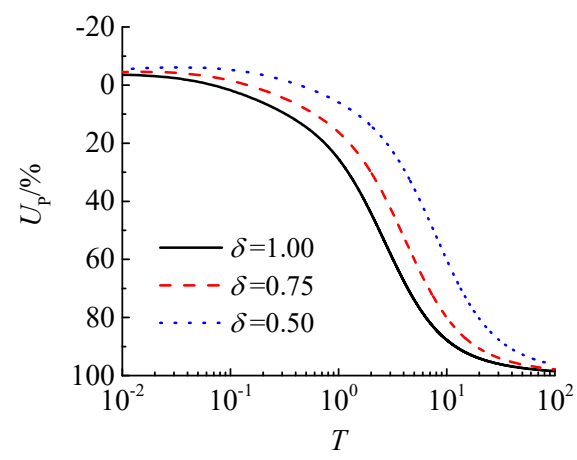

Fig. 8 The effect of the parameter $\delta$ on the consolidation degree. 
The degree of consolidation curves in Figure 8 also confirm this effect. The solid line in the figure represents the consolidation degree curve without considering the smearing effect. It is not difficult to see that the curve is always located at the bottom during the rheological consolidation process. Similar to previous studies [16, 17], with the decrease of the disturbance, the consolidation rate of soft clay foundation will gradually decrease, that is, the consolidation process will slow down. For instance, when $\mathrm{T}=10, \delta$ is set to $1.00,0.75$ and 0.50 , respectively, the corresponding consolidation degree $U_{P}$ is $0.9,0.8$ and 0.6 , respectively.

\subsection{Effects of applied load on rheological consolidation}

The conventional elastic consolidation theory indicates that the consolidation rate of the foundation is unrelated to the factor of applied load, but in fact, the external load is also a primary factor in determining the foundation consolidation process [44]. To investigate the influence of external load $\mathrm{p}_{0}$ on the rheological consolidation characteristics of sand drain foundation, Figure 9 and Figure 10 show the variation curves of normalized pore pressure $U$ and consolidation degree $U_{P}$ with $T$ under different loads.

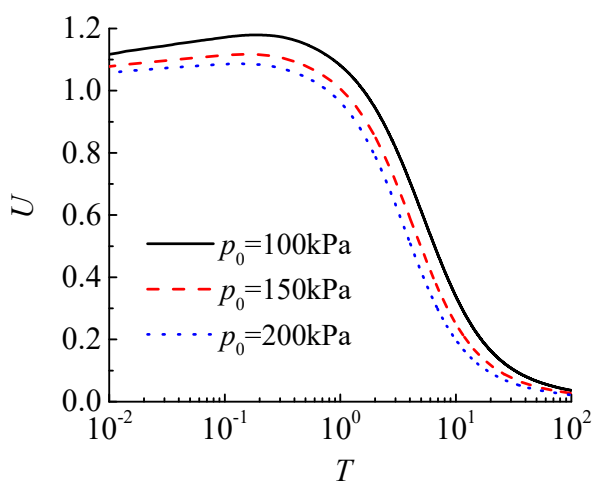

Fig. 9 The effect of the parameter $p_{0}$ on the pore pressure.

As observed, external load $\left(\mathrm{p}_{0}\right)$ has a great impact on elastic viscoplastic consolidation of sand drain foundations. As the upper load increases, the pore pressure and consolidation degree curves begin to shift downward, and as the load increases, the degree of deviation is higher. It is manifested in the early stage of consolidation as the increase of external load $\mathrm{p}_{0}$ reduces the accumulation rate of pore pressure and the corresponding peak pore pressures. This weakens the " Mandel-like effect " of pore pressure in the foundation soil and accelerates the overall dissipation rate of pore pressure in the late stage of consolidation. This conclusion is similar to the explanation of the influence mechanism of external load on 1D consolidation characteristics [45].

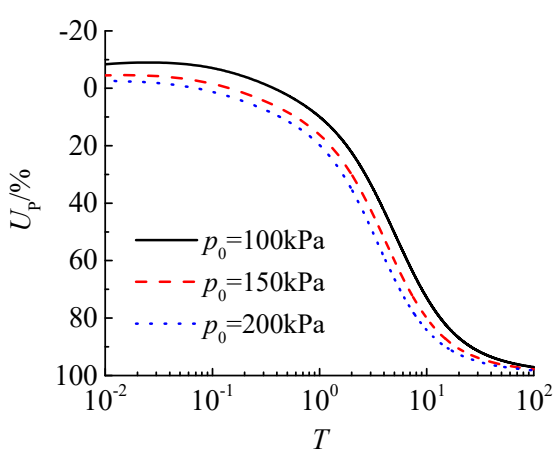

Fig. 10 The effect of the parameter ${ }^{p_{0}}$ on the consolidation degree.

\section{Conclusions}

Soil viscosity or primary and secondary consolidation coupling mechanisms are the main reasons for the increase in pore pressure, which are unrelated to the non-Darcy characteristics of seepages. The non-Darcy characteristics considering seepage delay the consolidation rate of sand drain foundation and lead to the increased pore pressure at the beginning of the consolidation. When the degree of soil disturbance is greater, the increase in pore pressure is stronger, while the reduction of the external load has a similar effect. Additionally, the existence of the smearing effect will significantly slow down the overall dissipation rate of pore pressure in sand drain foundations but an increase of the external load can speed up the process of the foundation consolidation.

\section{Data Availability}

Te data used to support the findings of this study are available from the corresponding author upon request.

\section{Conflicts of Interest}

Te authors declare that they have no conflicts of interest

\section{Funding Statement}

This work was supported by the National Key R\&D Program of China(no. 2017YFC0405002).

\section{References}

1. Braja M. DAS. Advanced soil mechanics[M]. U. S: Taylor \& Francis, 2014.

2. Barron R A. Consolidation of fine grained soils by drains wells[J]. Transactions of ASCE, 1948, 113: 718-742.

3. Hansbo S, Jamiolkowski M, Kok L. Consolidation by vertical drains[J]. Geotechique, 1981, 31(1): 45-46.

4. Xie Kanghe, Zeng Guo. Consolidation theories for drain wells under equal strain condition[J]. Journal of Geotechnical Engineering, 1989, 11(2): 3-17. 
5. XU Yan, WU Fang, XIE Kanghe, et al. Analytic solution of consolidation equation for soft soil with vertical drains subject to non-uniformly distributed initial pore water pressure [J]. Journal of Hydraulic Engineering, 2008, 39(7): 829-835.

6. CHEN Guohong, XIE Kanghe, CHENG Yongfeng, et al. Analytical solution for consolidation of sanddrained ground considering variation of permeability coefficient in smeared zone[J]. Journal of Zhejiang University (Engineering Science), 2011, 45(4): 665670.

7. Deng Y B, Xie K H, Lu M M. Consolidation by vertical drains when the discharge capacity varies with depth and time[J]. Computers and Geotechnics, 2013, 48: 1-8.

8. XU Bo, LEI Guohui, ZHENG Qiang, et al. Solution of consolidation by surcharge preloading considering compressibility and varying hydraulic conductivities in smear zone[J]. Rock and Soil Mechanics, 2014, 35(6): 1607-1616.

9. HU Yayuan. A Hansbo's consolidation solution of sand-drained ground with impeded boundaries under vacuum and surcharge preloading[J]. Journal of Engineering, 2018, 40(7): 783-792.

10. Mesri G, Rokhasr A. Theory of consolidation for clays[J]. Clay and Clay Mineral, 1974, 19(3): 151158.

11. ZHUANG Yingchun, LIU Shiming, XIE Kanghe. Study on nonlinearity of one-dimensional consolidation coefficient of Xiaoshan clay[J]. Journal of Rock Mechanics and Engineering, 2005, 24(24): 4565-4569.

12. Berry P L, Wilknson W B. The radial consolidation of clay soils[J]. Geotechnique, 1969, 19(2): 253-284.

13. Basak P, Madhav R. Analytical solutions of sand drain problems[J]. Journal of the Geotechnical Engineering Division, ASCE, 1978, 104(1): 129-135.

14. ZHOU Qi, LIU Hanlong, CHEN Zhi-bo. Non-linear radial consolidation of sand-drained ground with varying volume compressibility and horizontal permeability[J]. Rock and Soil Mechanics, 2007, 28(S1): 855-858.

15. Guo Biao, HAN Ying, GONG Xiaonan, et al. Nonlinear consolidation behavior of sand foundation with both horizontal and vertical drainage[J]. Journal of Shenzhen University(Science and Engineering), 2010, 27(4): 459-463.

16. ZHANG Haiqiu, GAO Guangyun, LEI Dan. An Analytical solution of radial consolidation considering three nonlinear relationships of soft soils[J]. Journal of Engineering Geology, 2015, 23(4): 681-686.

17. XIA Gaoxiang, ZHOU Feng, LIU Jiacai. Radical consolidation solution of non-linear single sanddrained foundation considering well resistance changing with time[J]. Journal of Nanjing Tech University(Natural Science Edition), 2016, 38(4):105-113.
18. HUANG Chaoxuan, DENG Yuebao, HU Guojie. Consolidation theory for prefabricated vertical drain assuming elliptic cross section and nonlinear well resistance $[\mathrm{J}]$. Journal of Rock Mechanics and Engineering, 2017, 36(3): 725-735.

19. GUO Xiao, XIE Kanghe, LU Mengmeng, et al. Nonlinear analytical solution for consolidation of vertical drains by straight-line vacuum preloading method $[\mathrm{J}]$. Journal of Central South University(Natural Science Edition), 2018, 49(2): 384-392.

20. Bjerrum L. Embankments on soft ground: State of threat report [C]. Proceedings of Specialty Conference on Performance of Earth and Earth Supported Structures, 1972: 1-54.

21. LI Xibin, XIE Kanghe, CHEN Fu-quan. One dimensional consolidation and permeability tests considering stress history and rheological characteristic of soft soils[J]. Journal of Hydraulic Engineering, 2013, 44(1): 18-25.

22. LUO Qingzi, CHEN Xiaoping, WANG Sheng, et al. An experimental study of time-dependent deformation behaviour of soft soil and its empirical model[J]. Rock and Soil Mechanics, 2016, 37(1): 6675 .

23. LIU Xingwang, XIE Kanghe, PAN Qiu, et al. Viscoelastic consolidation theories of soils with vertical drain wells $[\mathrm{J}]$. China Civil Engineering Journal, 1998, 31(1):10-19.

24. WANG Ruichun, XIE Kanghe. Analytical solution for viscoelastic consolidation by vertical drains under time-dependent loading[J]. China Civil Engineering Journal, 2001, 34(6): 93-99.

25. Huang M H, Li J C. Consolidation of viscoelastic soil by vertical drains incorporating fractional-derivative model and time-dependent loading. International Journal for Numerical and Analytical Methods in Geomechanics, 2018, 43(1): 239-256.

26. YUAN Jing, GONG Xiaonan, YI Deqing. Comparison study on rheological constitutive models[J]. Journal of Rock Mechanics and Engineering, 2001, 20(6): 772-779.

27. YAO Yangping. Unified Hardening model for soils and its development[J]. Industrial Construction, 2008, 38(8): 1-5.

28. Yao Y P, Kong L M, Hu J. An elastic-viscous-plastic model for overconsolidated clays[J]. Sci China Tech Sci, 2013, 56(2): 441-457.

29. HU Jing, YAO Yangping. 1D-consolidation analysis based on UH model considering time effect[J]. Journal of Beijing University of Aeronautics and Astronautics, 2015, 41(8): 1492-1498.

30. LIU Zhongyu, ZHU Xinmu, XIA Yangyang, et al. Analysis of radial elastic visco-plastic consolidation of ideal sand-drained ground[J]. Journal of Underground Space and Engineering, 2019, 47(5): 640-647.

31. Hansbo S. Consolidation of clay with special 
reference to influence of vertical sand drain[J]. Swedish Geotechnical Institute, 1960, 18(1): 45-50.

32. Slepicka F. Contribution to the solution of the filtration law[C] International union of Geodesy and Geophysics, Commission of Subterranean Waters. Finland, 1960: 245-258.

33. QI Tian, XIE Kanghe, HU Anfeng, et al. Laboratorial study on non-Darcy seepage in Xiaoshan clay[J]. Journal of Zhejiang University (Engineering Science), 2007, 41(6): 1023-1028.

34. Walker R, Indraratna B, Rujikiatkamjorn C. Vertical drain consolidation with non-Darcy flow and voidratio-dependent compressibility and permeability[J]. Geotechnique, 2012, 62(11): 985-997.

35. LI Feifei, XIE Kanghe, DENG Yuebao. Analytical solution for consolidation by vertical drains with exponential flow under vacuum preloading[J]. Journal of Central South University(Natural Science Edition), 2015, 46(3): 1075-1081.

36. GAO Guangyun, NIE Chunxiao, ZHANG Hangqiu, et al. Radial consolidation solution of plastic wick drain combined vacuum preloading $[\mathrm{J}]$. Journal of Tongji University(Natural Science), 2017, 45(9): 1290-1297.

37. Analytical solution for radial consolidation of sand drains foundation based on non-darcy seepage $[\mathrm{J}]$. Journal of Tongji University(Natural Science), 2013, 41(9): 1293-1297+1391.

38. Xiao Guo, Kang-He Xie, and Yue-Bao Deng, et al. Consolidation by Prefabricated Vertical Drains with a Threshold Gradient[J]. Mathematical Problems in Engineering, 2014, 2014(2): 1-9.

39. ZHOU Yu, XIE Kanghe, LIU Xing-wang. Analytical solution for vertical drains considering threshold gradient and smear effect $[\mathrm{J}]$. Engineering Mechanics, 2014, 31(2): 103-109.

40. DENG Yuebao, XIE Kanghe, LI Feifei, et al. Nonlinear finite element analysis of consolidation for vertical drained ground with parameters determined from GDS consolidation permeability tests[J]. Journal of Rock Mechanics and Engineering, 2014, 33(S2): 4203-4210.

41. LIU Zhongyu, JIAO Yang. Consolidation of ground with ideal sand drains based on Hansbo's flow[J]. Journal of Geotechnical Engineering, 2015, 37(5): 792-801.

42. Bergado D T, Singh N, Sim S H, et al. Improvement of soft Bangkok clay using vertical geotextile band drains compared with granular piles[J]. Geotextiles and Geomembranes, 1990, 9(3): 203-231.

43. Madhav R, Park Y M, Miura N. Modelling and study of smear zones around band shaped drains[J]. Soils and Foundations, 1993, 33(4): 135-147.

44. LIU Zhongyu, JIAO Yang. Radial consolidation of sand drained ground Considering Hansbo's Flow[J]. Journal of Zhengzhou University (Science Edition), 2014, 46(2): 116-119.

45. LI Chuanxun, HU Anfeng, XIE Kanghe, et al. Semi- analytical solution of one-dimensional consolidation with non-darcy flow considering time-dependent loading $[\mathrm{J}]$. Journal of Rock Mechanics and Engineering, 2011, 30(S2): 3937-3943. 